CLINICAL STUDY

\title{
Incidence and predictors of all-cause and site-specific cancer in type 2 diabetes: the Fremantle Diabetes Study
}

\author{
Dianna J Magliano ${ }^{1,2}$, Wendy A Davis ${ }^{3}$, Jonathan E Shaw ${ }^{1}$, David G Bruce ${ }^{3}$ and Timothy M E Davis ${ }^{3}$ \\ ${ }^{1}$ Baker IDI Heart and Diabetes Institute, Melbourne, Victoria, Australia, ${ }^{2}$ School of Public Health and Preventive Medicine, Monash University, Melbourne, \\ Victoria, Australia and ${ }^{3}$ School of Medicine and Pharmacology, Fremantle Hospital, University of Western Australia, PO Box 480, Fremantle, \\ Western Australia 6959, Australia \\ (Correspondence should be addressed to T M E Davis, Australia; Email: tdavis@cyllene.uwa.edu.au)
}

\begin{abstract}
Objective: To explore the relationship between diabetes and cancer.

Design: The Fremantle Diabetes Study (FDS) was a community-based longitudinal observational study of 1426 subjects, 1294 of which had type 2 diabetes.

Methods: The FDS type 2 cohort and four age-, sex- and postcode-matched controls per case were followed for cancer events from 1993 until mid-2010 and incidence rate ratios (IRRs) were calculated. Competing risks proportional hazards models generated risk factors for incident cancers in the diabetic group.

Results: There were 309 first cancers over 13051 patient-years, or 2368 (95\% confidence interval (95\% CI) 2111-2647)/100 000 patient-years in the diabetes patients vs 1131 over 60324 patient-years (1875 (1769-1987)/100 000 patient-years) in the controls. For those aged $\geq 45$ years, the risk of all-cause cancer was elevated in type 2 diabetic men (IRRs 1.23, 95\% CI 1.04-1.45) and women (1.30, 1.06-1.59). The incidence of colorectal cancer was increased (1.36, 1.01-1.82), especially in diabetic men aged 75-84 years $(2.14,1.22-3.64)$. Age at diabetes diagnosis (sub-hazard ratio 1.05, 1.02-1.09), calcium channel blocker therapy $(2.37,1.39-4.06)$, recent exercise $(2.11,1.06-4.20)$ and serum total cholesterol $(0.68,0.52-0.88)$ increased colorectal cancer risk. Pancreatic cancer was also more frequent in the diabetic patients (IRR 2.26, 1.20-4.10). Diabetic men and women had similar risks of prostate and breast cancer to those of controls $(0.83,0.59-1.14$ and $0.86,0.52-1.36)$.

Conclusions: Type 2 diabetes is associated with a moderately increased cancer risk in well-characterised community-based patients, especially pancreatic cancer and colorectal cancer in older men. Recommended cancer screening should be considered as part of routine diabetes management.
\end{abstract}

European Journal of Endocrinology 167 589-599

\section{Introduction}

The weight of evidence, derived largely from pooled cohort studies, administrative databases and metaanalyses, suggests that type 2 diabetes is associated with an increased risk of a number of cancers including those of liver (1), pancreas (2), colon and rectum (3), breast (4), endometrium (5) and bladder (6), while there may be a decreased risk in the case of prostate cancer (7). Associations between diabetes and cancer may, however, be confounded by co-incident risk factors including ageing, obesity and insulin resistance, an imprudent diet and lack of physical activity (8). In addition, some diabetes treatments may increase $(9,10,11)$ or decrease (12) cancer risk. A further issue that can confound interpretation of cancer rates in diabetes is the occurrence of non-cancer-related deaths such as those from cardiovascular disease. Without consideration of such competing risks, estimation of predictors of incident cancer might be confounded (13).
There are few prospective studies that have explored cancer incidence, risk factors and competing risks in detail in community-based type 2 diabetic patients. Such studies would facilitate a more accurate assessment of the independent contribution of diabetes and diabetesrelated variables to the development of cancer, which, even if small, would have important consequences at a population level. We have, therefore, examined the relationship between diabetes and total and major sitespecific cancer in a well-characterised prospectively studied cohort of Australian adults with diabetes and in age-, sex- and postcode-matched non-diabetic controls.

\section{Materials and methods}

\section{Patients}

The Fremantle Diabetes Study (FDS) Phase I was a longitudinal observational cohort study of patients 
from a postcode-defined urban community of 120097 people. Descriptions of recruitment, sample characteristics including classification of diabetes type, and details of non-recruited patients have been published elsewhere (14). Of 2258 diabetic patients identified between 1993 and 1996, 1426 (63\%) were recruited to the FDS and 1294 had clinically diagnosed type 2 diabetes. Eligible patients who declined participation were a mean of 1.4 years older than participants, but their sex distribution, the proportion with type 2 diabetes and their use of blood glucose-lowering therapies were similar (15). The FDS protocol was approved by the Human Rights Committee at Fremantle Hospital and all subjects gave informed consent before participation.

\section{Selection of controls}

It is compulsory for all Australians aged 18 years and over to vote in Federal and State elections and thus all adults resident in the FDS catchment area are listed on the electoral roll. Four age-, sex- and postcode-matched non-diabetic controls were randomly selected from this source for each FDS participant at the time of FDS study entry. The requirement for postcode matching was based on the fact that there are substantial socioeconomic and environmental differences between residential districts within the FDS catchment area. Some of the lowest socio-economic districts are located adjacent to heavy industry and thus exposed to potential carcinogens $(16,17)$. Non-diabetic status was defined as diabetes not being coded at any time on any Western Australia health database. Matches could not be made for five children and four elderly participants, and these patients were excluded from estimation of incident rate ratios, leaving 1289 (99.6\%) diabetic participants who were matched with 5156 non-diabetic controls. Five controls died just before entry into FDS by their matched case and were therefore excluded. Because the range of data available for the control subjects was limited to date of birth, sex and postcode, they were used only for estimation of incidence rate ratios (IRRs; see below).

To provide additional comparative control data, we used published data from the Australian Cancer Database 2007 (18). This source did not allow analysis by diabetes status. The overall national cancer incidence remained relatively stable over the period of follow-up in this study, being an average 1192/100 000 and ranging from $1149 / 100000$ in 1999 to $1236 /$ 100000 in 2007 for those 45 years and older.

\section{Cancer registration, hospitalisation and mortality ascertainment}

All deaths, hospitalisations and cancer registrations in the state of Western Australia are recorded in the Western Australia Data Linkage System (19), which was used to provide FDS patient and control outcomes from 1982 until end-June 2010. Incident hospitalisation/registration for cancer events was defined as a hospital admission/cancer registration with principal or secondary diagnosis of malignant cancer but excluding non-melanocytic skin cancer (NMSC), equivalent to an International Classification of Disease (ICD)-9 code 140-208 (excluding 173), 238.4, 238.71, 238.72, $238.75,238.76,238.79$ or 273.3 , or an ICD-10 code of C00-C96 (excluding C44), D45, D46, D47.1 or D47.3. The documentation of cancer in death certificates was also used to define incident cancer, even if the cause of death was not cancer. As has been done in similar analyses (20), the development of a cancer at one site did not exclude subjects from analyses of a first cancer at another site.

\section{Statistical analysis}

The computer packages Stata IC 10.0 (StataCorp LP, College Station, TX, USA) and SPSS for Windows (version 17.0; SPSS Inc., Chicago, IL, USA) were used for statistical analysis. Data are presented as proportions, mean \pm s.D., geometric mean (s.D. range), or, in the case of variables that did not conform to a normal or log-normal distribution, median and inter-quartile range (IQR). For independent samples, two-way comparisons for proportions were by Fisher's exact test, for normally distributed variables by Student's $t$-test, and for nonnormally distributed variables by Mann-Whitney $U$ test. A two-tailed significance level of $P<0.05$ was used throughout. Ten-year age- and sex-specific incident rates of any (excluding NMSC) and site-specific cancers for the FDS cohort were compared with those derived for the non-diabetic controls, and IRRs were derived. Ten-year age groups starting at 45 years of age were selected due to the middle to older age of people with type 2 diabetes. In addition, Cox proportional hazards modelling was used to generate hazard ratios (HRs) for cancer in those with type 2 diabetes adjusting for gender. Owing to the presence of covariates strongly associated with age, age was used as the timescale with left truncation of age at study entry (21).

Associations between potential predictors and incident cancer were explored with competing risk models. The predictors of the cumulative incidence of cancer in FDS participants, accounting for the competing event of non-cancer death, were ascertained using the Fine and Gray model (13), which extends the Cox proportional hazards model to competing risk data by considering the sub-distribution hazard. This method was used because traditional Cox models are limited by the assumption that the event of interest will eventually occur. In a study of cancer, for example, a subject dying from a stroke (a competing risk) before any cancer was diagnosed is treated as if they were right censored and could later develop cancer. The Fine and Gray model controls for this bias and yields a sub-HR (sHR), which is the ratio of hazards associated with the cumulative 
incidence function (or absolute cause-specific risk) under varying values of a given covariate. The sHR may be interpreted as a HR. Competing risk was defined separately for each cancer site as mortality from causes other than that of interest (e.g. death from a non-cancer cause or from a cancer at another site).

Age was used as the timescale with left truncation of age at study entry (21). The most parsimonious model of predictors of incident cancer was determined. All clinically plausible baseline variables at $P \leq 0.20$ in bivariate analyses were considered for entry, including demographic and diabetes-related factors, the presence of other complications and risk factors for cancer. As serum LDL-cholesterol was calculated and therefore missing for values of serum triglycerides $\geq 4.5 \mathrm{mmol} / \mathrm{l}$, it was not considered for entry into the models. A formal check of proportionality was undertaken by the use of time-varying covariate effects. The observed nonproportional hazards for age at diagnosis of diabetes for all-cause cancer was accounted for by stratifying the analyses by age of diagnosis $(<60$ and $\geq 60$ years).

\section{Results}

\section{Baseline patient characteristics}

At study entry, the 1294 FDS type 2 participants had a mean \pm s.D. age of $64.1 \pm 11.3$ years, $48.8 \%$ were male and their median (IQR) diabetes duration was 4.0 (1.0-9.0) years.

\section{Cancer incidence}

A previous cancer history was recorded for 110 (8.5\%). Of the remaining 1184 participants, over one quarter (309 or $26.1 \%$ ) were hospitalised for, were registered with or died from/with malignant cancer during 13051 patient-years (mean \pm s.D. $11.0 \pm 5.5$ years) of follow-up to the first diagnosis of cancer after baseline, death or end-June 2010, whichever came first. This represented a crude incidence of 2368 (95\% confidence interval (95\% CI) 2111-2647) events/ 100000 patient-years. There were 1131 databaseidentified cancer events in the controls $(23.3 \%)$ over 60324 patient-years, representing a crude incidence of 1875 (1769-1987)/100 000 patient-years.

Among 1282 without a history of colorectal cancer at entry, $63(4.9 \%)$ developed colorectal cancer. The crude incidence of colorectal cancer was 416 (95\% CI 320-533)/100 000 patient-years. Men had a significantly higher incidence of colorectal cancer than women with an IRR of 1.88 (95\% CI 1.10-3.26, $P=0.015)$. Among 615 men free of prostate cancer at entry, $45(7.3 \%)$ developed prostate cancer, a crude incidence of 661 (95\% CI 482-884)/100 000 patientyears. Among 644 women free of breast cancer at baseline, 22 (3.4\%) developed breast cancer with a crude incidence of 278 (95\% CI 174-420)/100 000 patient-years. Excluding two cases of pancreatic cancer that were diagnosed before diabetes diagnosis, 18 (1.4\%) developed pancreatic cancer during follow-up, a crude incidence of 117 (95\% CI 69-185)/100 000 patient-years.

\section{Incidence rate and HRs of cancer in patients vs controls}

Table 1 summarises IRRs for any malignancy, and colorectal, breast, prostate and pancreatic cancer for the FDS type 2 diabetic cohort in comparison with the age-, sex- and postcode-matched controls. All-cause, colorectal and pancreatic cancers were increased in type 2 diabetes, and the incidence of all-cause cancer was significantly elevated in both men and women with diabetes. The incidence of colorectal cancer for 75- to 84-year-old men with type 2 diabetes was 2.14 times higher than controls, while the corresponding incidence for women was increased by $47 \%$, but this was not statistically significant. Unadjusted and sex-adjusted HRs for first cancer at any and each site in the prevalent type 2 diabetes cohort compared with the matched non-diabetic cohort following entry into the FDS are presented in Supplementary Table 1, see section on supplementary data given at the end of this article. The HRs for diabetes were consistent with the IRRs in Table 1, while all cancers except breast were associated with increasing age.

The IRRs for cancer in patients in the FDS cohort $\geq 45$ years relative to national notifications in the same age group were $2.04(1.82-2.29)$ for all-cause cancer (1.81 (1.50-2.15) for women and 2.08 (1.79-2.40) for men), $2.44(1.88-3.12)$ for colorectal cancer (2.06 (1.32-3.07) for women and 2.71 (1.93-3.71) for men), 1.70 (1.24-2.28) for prostate cancer, 1.05 (0.66-1.59) for breast cancer and 4.11 (2.43-6.49) for pancreatic cancer.

\section{Bivariate predictors of incident cancer}

Two patients who were lost to follow-up were excluded from analyses of risk factors for incident cancer. This left 1182 participants without a previous history of cancer at study entry who did or did not go on to develop a malignant cancer during follow-up. In bivariate analysis of baseline variables (see Table 2), older age at study entry and at diabetes diagnosis, male sex and current or former smoking were significantly associated with any incident cancer. A lower prevalence of retinopathy, lower $\mathrm{HbA1c}$, lower total serum cholesterol and lower serum LDL-cholesterol were associated with the development of cancer during follow-up.

For site-specific cancer (see Supplementary Table 2, see section on supplementary data given at the end of this article), older age at study entry and diabetes diagnosis, male sex, recent exercise, total serum 
Table 1 Age-specific incidence rate per 100000 patient-years and incidence rate ratio (IRR) vs age-, sex- and postcode-matched nondiabetic controls of first record (hospitalisation, cancer register and death) of all (excluding NMSC) and site-specific cancer for persons aged $\geq 45$ years.

\begin{tabular}{|c|c|c|c|c|c|c|}
\hline \multirow[b]{2}{*}{ Cancer type } & \multicolumn{5}{|c|}{ Age group (years) } & \multirow[b]{2}{*}{ Total } \\
\hline & $45-54$ & $55-64$ & $65-74$ & $75-84$ & $85+$ & \\
\hline \multicolumn{7}{|l|}{ All (both genders) } \\
\hline FDS: no. of cancers & 12 & 36 & 130 & 109 & 20 & 307 \\
\hline FDS: years & 1271.9 & 2986.8 & 4724.8 & 3003.4 & 613.2 & 12600.1 \\
\hline FDS: IR & 943.5 & 1205.3 & 2751.5 & 3629.2 & 3261.6 & 2436.5 \\
\hline Control: no. of cancers & 27 & 120 & 413 & 450 & 117 & 1127 \\
\hline Control: years & 5338.5 & 12814.3 & 20956.0 & 15534.1 & 3772.9 & 58415.7 \\
\hline Control: IR & 505.8 & 936.5 & 1970.8 & 2896.9 & 3101.1 & 1929.3 \\
\hline IRR & 1.87 & 1.29 & 1.40 & 1.25 & 1.69 & 1.26 \\
\hline $95 \% \mathrm{Cl}$ & $0.86-3.81$ & $0.86-1.88$ & $1.14-1.71$ & $1.01-1.55$ & $0.12-1.70$ & $1.11-1.43$ \\
\hline \multicolumn{7}{|l|}{ All (women) } \\
\hline FDS1: no. of cancers & 7 & 15 & 38 & 50 & 13 & 123 \\
\hline FDS1: years & 677.2 & 1511.1 & 2462.9 & 1725.5 & 441.1 & 6817.8 \\
\hline FDS1: IR & 1033.7 & 992.6 & 1542.9 & 2897.7 & 2947.0 & 1804.1 \\
\hline Control: no. of cancers & 19 & 50 & 143 & 161 & 70 & 443 \\
\hline Control: years & 2845.5 & 6634.3 & 108230.0 & 8924.7 & 2676.5 & 31911.0 \\
\hline Control: IR & 667.7 & 753.7 & 1320.4 & 1804.0 & 2615.3 & 1388.2 \\
\hline IRR & 1.55 & 1.32 & 1.17 & 1.61 & 1.13 & 1.30 \\
\hline $95 \% \mathrm{Cl}$ & $0.55-3.85$ & $0.69-2.38$ & $0.79-1.68$ & $1.15-2.22$ & $0.57-2.05$ & $1.06-1.59$ \\
\hline \multicolumn{7}{|l|}{ All (men) } \\
\hline FDS1: no. of cancers & 5 & 21 & 92 & 59 & 7 & 184 \\
\hline FDS1: years & 594.7 & 1475.7 & 2261.9 & 1277.9 & 172.1 & 5782.3 \\
\hline FDS1: IR & 840.7 & 1423.1 & 4067.4 & 4616.9 & 4068.1 & 3182.1 \\
\hline Control: no. of cancers & 8 & 70 & 270 & 289 & 47 & 684 \\
\hline Control: years & 2493.1 & 6180.0 & 10126.0 & 6609.3 & 1096.3 & 26504.7 \\
\hline Control: IR & 320.9 & 1132.7 & 2666.4 & 4372.6 & 4287.1 & 2580.7 \\
\hline IRR & 2.62 & 1.30 & 1.53 & 1.06 & 0.95 & 1.23 \\
\hline $95 \% \mathrm{Cl}$ & $0.67-9.08$ & $0.76-2.15$ & $1.19-1.94$ & $0.78-1.40$ & $0.36-2.11$ & $1.04-1.45$ \\
\hline \multicolumn{7}{|l|}{ Colorectal (both genders) } \\
\hline FDS1: no. of cancers & 1 & 3 & 21 & 31 & 7 & 63 \\
\hline FDS1: years & 1336.8 & 3299.5 & 5531.1 & 3733.5 & 751.9 & 14652.8 \\
\hline FDS1: IR & 74.8 & 90.9 & 379.7 & 830.3 & 931.0 & 430.0 \\
\hline Control: no. of cancers & 3 & 17 & 73 & 80 & 30 & 203 \\
\hline Control: years & 5477.0 & 13509.2 & 23058.5 & 17898.7 & 4450.1 & 64393.55 \\
\hline Control: IR & 54.8 & 125.8 & 316.6 & 447.0 & 674.1 & 315.2 \\
\hline IRR & 1.37 & 0.72 & 1.20 & 1.86 & 1.38 & 1.36 \\
\hline $95 \% \mathrm{Cl}$ & $0.03-17.01$ & $0.14-2.50$ & $0.70-1.97$ & $1.19-2.84$ & $0.51-3.12$ & $1.01-1.82$ \\
\hline \multicolumn{7}{|l|}{ Colorectal (women) } \\
\hline FDS1: no. of cancers & 1 & 1 & 8 & 10 & 4 & 24 \\
\hline FDS1: years & 729.5 & 1714.4 & 2811.0 & 2083.8 & 513.8 & 7852.6 \\
\hline FDS1: IR & 137.1 & 58.3 & 284.6 & 479.9 & 778.5 & 305.6 \\
\hline Control: no. of cancers & 2 & 4 & 22 & 32 & 15 & 75 \\
\hline Control: years & 2938.6 & 7027.5 & 11664.9 & 9826.7 & 3030.4 & 34488.1 \\
\hline Control: IR & 68.1 & 56.9 & 188.6 & 325.6 & 495.0 & 217.5 \\
\hline IRR & 2.01 & 1.02 & 1.51 & 1.47 & 1.57 & 1.41 \\
\hline $95 \% \mathrm{Cl}$ & $0.03-38.69$ & $0.02-10.36$ & $0.58-3.52$ & $0.65-3.07$ & $0.38-4.94$ & $0.85-2.25$ \\
\hline \multicolumn{7}{|l|}{ Colorectal (men) } \\
\hline FDS1: no. of cancers & 0 & 2 & 13 & 21 & 3 & 39 \\
\hline FDS1: years & 607.3 & 1585.1 & 2720.0 & 1649.7 & 238.1 & 6800.2 \\
\hline FDS1: IR & 0 & 126.2 & 477.9 & 12723.0 & 1260.1 & 573.5 \\
\hline Control: no. of cancers & 1 & 13 & 51 & 48 & 15 & 128 \\
\hline Control: years & 2538.4 & 6481.6 & 11393.7 & 8072.0 & 1419.7 & 29905.4 \\
\hline Control: IR & 39.4 & 200.6 & 447.6 & 594.7 & 1056.6 & 428.0 \\
\hline IRR & 0 & 0.63 & 1.07 & 2.14 & 1.19 & 1.34 \\
\hline $95 \% \mathrm{Cl}$ & - & $0.07-2.78$ & $0.53-1.99$ & $1.22-3.64$ & $0.22-4.22$ & $0.91-1.93$ \\
\hline \multicolumn{7}{|l|}{ Prostate } \\
\hline FDS1: no. of cancers & 1 & 5 & 25 & 14 & 0 & 45 \\
\hline FDS1: years & 607.2 & 1573.0 & 2582.5 & 1585.8 & 254.1 & 6602.7 \\
\hline FDS1: IR & 164.7 & 317.9 & 968.0 & 882.8 & 0 & 681.5 \\
\hline Control: no. of cancers & 1 & 25 & 94 & 106 & 13 & 239 \\
\hline Control: years & 2538.9 & 6399.9 & 11009.3 & 7664.2 & 1322.2 & 28934.6 \\
\hline Control: IR & 39.4 & 390.6 & 853.8 & 1383.0 & 983.2 & 826.0 \\
\hline IRR & 4.18 & 0.81 & 1.13 & 0.64 & 0 & 0.83 \\
\hline $95 \% \mathrm{Cl}$ & $0.05-328.2$ & $0.24-2.16$ & $0.70-1.78$ & $0.34-1.12$ & - & $0.59-1.14$ \\
\hline
\end{tabular}




\begin{tabular}{|c|c|c|c|c|c|c|}
\hline \multirow[b]{2}{*}{ Cancer type } & \multicolumn{5}{|c|}{ Age group (years) } & \multirow[b]{2}{*}{ Total } \\
\hline & $45-54$ & $55-64$ & $65-74$ & $75-84$ & $85+$ & \\
\hline \multicolumn{7}{|l|}{ Breast } \\
\hline FDS1: no. of cancers & 2 & 6 & 6 & 7 & 1 & 22 \\
\hline FDS1: years & 724.0 & 1651.3 & 2726.7 & 2040.2 & 516.5 & 7658.8 \\
\hline FDS1: IR & 276.2 & 363.3 & 220.0 & 343.1 & 193.6 & 287.3 \\
\hline Control: no. of cancers & 20 & 34 & 38 & 19 & 0 & 111 \\
\hline Control: years & 2804.4 & 6652.1 & 11210.6 & 9519.4 & 2925.7 & 33112.2 \\
\hline Control: IR & 713.2 & 511.1 & 339.0 & 199.6 & 0 & 335.2 \\
\hline IRR & 0.39 & 0.71 & 0.65 & 1.72 & - & 0.86 \\
\hline $95 \% \mathrm{Cl}$ & $0.04-1.59$ & $0.24-1.71$ & $0.22-1.55$ & $0.61-4.27$ & - & $0.52-1.36$ \\
\hline \multicolumn{7}{|l|}{ Pancreas (both genders) } \\
\hline FDS1: no. of cancers & 1 & 1 & 5 & 8 & 3 & 18 \\
\hline FDS1: years & 1340.8 & 3312.0 & 5590.4 & 3925.9 & 808.3 & 14977.4 \\
\hline FDS1: IR & 74.6 & 30.2 & 89.4 & 203.8 & 371.2 & 120.2 \\
\hline Control: no. of cancers & 2 & 4 & 11 & 10 & 8 & 35 \\
\hline Control: years & 5486.569 & 13606.0 & 23507.4 & 18494.5 & 4677.4 & 65771.8 \\
\hline Control: IR & 36.5 & 29.4 & 46.8 & 54.1 & 171.0 & 53.2 \\
\hline IRR & 2.05 & 1.03 & 1.91 & 3.77 & 2.17 & 2.26 \\
\hline $95 \% \mathrm{Cl}$ & $0.03-39.30$ & $0.02-10.38$ & $0.52-5.97$ & $1.29-10.61$ & $0.37-9.04$ & $1.20-4.10$ \\
\hline
\end{tabular}

$\mathrm{IR}$, incidence rate.

cholesterol, LDL-cholesterol, systolic blood pressure and antihypertensive therapy were associated with future colorectal cancer. Incident breast cancer in women was associated with higher alcohol consumption. Incident prostate cancer was associated with lower levels of albuminuria. Pancreatic cancer was associated with significantly higher fasting plasma glucose and a trend to a male predominance.

\section{Independent predictors of incident cancer in patients with type 2 diabetes}

Table 3 shows the predictors of all-cause cancer among the cohort for all patients with type 2 diabetes. Male sex and age at diagnosis of diabetes predicted incident cancer for those aged $\geq 60$ years at diabetes diagnosis. For those younger than 60 years of age at diabetes diagnosis, smoking (current and ex-) independently predicted risk while an elevated urinary albumin:creatinine ratio was inversely associated. Older age at diabetes diagnosis independently predicted colorectal cancer and the use of calcium channel blockers and exercising both more than doubled the risk of colorectal cancer. Elevated total serum cholesterol was inversely associated with colorectal cancer. Metformin use independently predicted prostate cancer incidence while elevated fasting serum glucose and albuminuria appeared protective against prostate cancer. No competing risk analyses were performed for incident breast and prostatic cancer because the number of cases was small $(n \leq 22)$.

\section{Discussion}

The present data confirm that cancer is a common co-morbidity of type 2 diabetes. Nearly one-third of our community-based cohort developed cancer before or during an average 11 years of observation. Compared with age-, sex- and postcode-matched non-diabetic controls, the FDS type 2 patients had a significantly increased risk of incident all-cause cancer that was present for both genders and consistent across age groups. Among site-specific cancers, there was an excess risk of both colorectal and pancreatic cancers. For colorectal cancer, the risk was greatest (more than double that of controls) in men aged 75-84 years. Men and women with type 2 diabetes in our cohort had incidence rates of prostate and breast cancer, respectively, that were not significantly different to those of matched controls. A variety of diabetes-related and nondiabetes-related variables were associated with incident cancer in competing risk models that have potential implications for management.

Our estimated all-cause cancer IRRs for type 2 men (1.23) and women (1.30) are very close to those for people with diabetes in large population-based studies from Korea (1.24 and 1.33 respectively) (22) and Japan (1.27 and 1.21 respectively) (23). There are few similar data for predominantly Europid cohorts (24). A relatively small recent US study involving 599 diabetic patients found a HR of 1.22 relative non-diabetic controls (25). A Danish study utilising a populationbased register (26) found that men and women with diabetes were at $10 \%$ increased risk but only hospitalised patients were included and diabetes status was ascertained using inpatient coding alone. Because of differences in apparent relationships between diabetes and the various types of malignancy, analyses of associations with all-cause cancers have been discouraged (8). However, the consistency of the results of this and other studies $(22,23,24,26,27)$ suggests that there is a moderate diabetes-specific increase in overall 
cancer risk. Possible unifying underlying mechanisms include direct promotion of cell growth and an increase in the likelihood of metastasis through altered endothelial permeability by hyperglycaemia (28), while hyperinsulinaemia and elevated circulating insulin-like growth factor concentrations may also promote tumour growth (29). Our data suggest that the smoking-associated increased risk of many forms of cancer is greatest in diabetic patients who are $<60$ years of age.

Table 2 Baseline characteristics of people with type 2 diabetes and no history of malignant cancer (excluding NMSC and those with diabetes duration $\leq 1$ year at time of first cancer diagnosis) who did and did not develop cancer during follow-up. Data are percentage or mean \pm S.D. or median (IQR) or geometric mean (s.D. range).

\begin{tabular}{|c|c|c|c|}
\hline & No cancer & Incident cancer & $P$ value \\
\hline$n(\%)$ & $873(73.9 \%)$ & $309(26.1 \%)$ & \\
\hline Age (years) & $63.1 \pm 12.0$ & $65.2 \pm 9.2$ & 0.002 \\
\hline Sex (\% male) & $45.1^{-}$ & 59.5 & $<0.001$ \\
\hline \multicolumn{4}{|l|}{ Ethnic background (\%) } \\
\hline Anglo-Celt & 61.2 & 67.6 & \multirow[t]{3}{*}{0.13} \\
\hline Southern European & 19.8 & 16.8 & \\
\hline Other & 19.0 & 15.5 & \\
\hline Education beyond primary level (\%) & 74.7 & 74.3 & 0.88 \\
\hline Not fluent in English (\%) & 16.9 & 12.9 & 0.12 \\
\hline \multicolumn{4}{|l|}{ Smoking status (\%) } \\
\hline Never & 48.4 & 36.4 & \multirow[t]{3}{*}{0.001} \\
\hline Ex-smoker & 37.9 & 44.5 & \\
\hline Current smoker & 13.7 & 19.2 & \\
\hline Any exercise in past 2 weeks (\%) & 71.2 & 75.2 & 0.18 \\
\hline Alcohol consumption (standard drinks/day) & $0(0-0.4)$ & $0(0-0.8)$ & 0.12 \\
\hline Age at diabetes diagnosis (years) & $56.9 \pm 12.2$ & $59.7 \pm 9.9$ & $<0.001$ \\
\hline Diabetes duration (years) & $4.0(1.0-9.0)$ & $4.0(1.0-9.0)$ & 0.69 \\
\hline Fasting serum glucose (mmol/l) & $8.6(6.9-11.0)$ & $8.1(6.8-10.4)$ & 0.05 \\
\hline $\mathrm{HbA} 1 \mathrm{c}(\%)$ & $7.6(6.4-8.9)$ & $7.1(6.4-8.5)$ & 0.009 \\
\hline $\begin{array}{l}\text { Fasting serum insulin }(\mathrm{pmol} / \mathrm{l}) \text { in } \\
\text { non-insulin-treated patients }\end{array}$ & $74.6(38.3-145.5)$ & $73.4(39.1-137.8)$ & 0.74 \\
\hline \multicolumn{4}{|l|}{ Diabetes treatment (\%) } \\
\hline Diet & 31.3 & 33.7 & \multirow[t]{3}{*}{0.33} \\
\hline Oral glucose-lowering medications (OAD) & 55.9 & 56.6 & \\
\hline Insulin $\pm O A D$ & 12.8 & 9.7 & \\
\hline Metformin (\%) & 33.8 & 31.2 & 0.44 \\
\hline Sulphonylureas (\%) & 42.8 & 42.2 & 0.89 \\
\hline Body mass index $\left(\mathrm{kg} / \mathrm{m}^{2} ; \%\right)$ & $29.7 \pm 5.7$ & $29.4 \pm 4.9$ & 0.40 \\
\hline$<25.0$ & 17.4 & 17.5 & 0.69 \\
\hline $25.0-29.9$ & 40.5 & 37.9 & \\
\hline$\geq 30.0$ & 42.1 & 44.7 & \\
\hline \multicolumn{4}{|l|}{ Waist circumference $(\mathrm{cm})$} \\
\hline Men & $103.0 \pm 11.8$ & $103.2 \pm 11.2$ & 0.81 \\
\hline Women & $96.8 \pm 13.4$ & $97.3 \pm 12.0$ & 0.73 \\
\hline \multicolumn{4}{|l|}{ Waist:hip ratio } \\
\hline Men & $0.96 \pm 0.06$ & $0.95 \pm 0.05$ & 0.78 \\
\hline Women & $0.87 \pm 0.07$ & $0.86 \pm 0.06$ & 0.79 \\
\hline \multicolumn{4}{|l|}{ Obese by waist circumference (\%) } \\
\hline Men & 52.2 & 53.8 & 0.72 \\
\hline Women & 74.5 & 77.6 & 0.56 \\
\hline Systolic blood pressure (mmHg) & $150 \pm 24$ & $151 \pm 23$ & 0.43 \\
\hline Diastolic blood pressure $(\mathrm{mmHg})$ & $81 \pm 11$ & $80 \pm 11$ & 0.81 \\
\hline Taking antihypertensive medication (\%) & $49 . \overline{0}$ & $53 . \overline{7}$ & 0.17 \\
\hline ACE inhibitors & 22.2 & 19.1 & 0.26 \\
\hline$\beta$-Blockers & 14.8 & 19.1 & 0.09 \\
\hline Calcium channel blockers & 18.2 & 20.4 & 0.40 \\
\hline Total serum cholesterol (mmol/l) & $5.5 \pm 1.1$ & $5.3 \pm 1.0$ & 0.002 \\
\hline HDL-cholesterol (mmol/l) & $1.06 \pm 0.32$ & $1.06 \pm 0.33$ & 0.79 \\
\hline LDL-cholesterol (mmol/l) & $3.5 \pm 0.9$ & $3.3 \pm 0.9$ & 0.001 \\
\hline Serum triglycerides $(\mathrm{mmol} / \mathrm{l})$ & $1.9(1.1-3.3)$ & $1.8(1.1-3.1)$ & 0.26 \\
\hline Taking lipid-lowering medication (\%) & 10.0 & 12.1 & 0.33 \\
\hline Urinary albumin:creatinine ratio (ACR; $\mathrm{mg} / \mathrm{mmol}$ ) & $3.1(0.7-13.8)$ & $2.7(0.7-10.0)$ & 0.10 \\
\hline Peripheral neuropathy (\%) & 31.1 & 30.5 & 0.88 \\
\hline Any retinopathy (\%) & 17.9 & 12.3 & 0.024 \\
\hline Coronary heart disease (\%) & 27.5 & 27.5 & 1.00 \\
\hline Cerebrovascular disease (\%) & 10.0 & 8.7 & 0.58 \\
\hline Peripheral arterial disease (\%) & 28.2 & 28.5 & 0.94 \\
\hline
\end{tabular}


Table 3 Competing risk proportional hazards models exploring associations with all (excluding NMSC), colorectal and prostate incident cancer with age as the timescale. Data are sub-hazard ratios and $95 \%$ confidence intervals.

\begin{tabular}{|c|c|c|c|c|}
\hline & \multicolumn{2}{|c|}{ Any cancer } & \multirow[b]{2}{*}{$\begin{array}{c}\text { Colorectal cancer } \\
63 / 1282\end{array}$} & \multirow[b]{2}{*}{$\begin{array}{c}\text { Prostate cancer } \\
45 / 615\end{array}$} \\
\hline & $\begin{array}{c}\text { Age at diabetes } \\
\text { diagnosis }<60 \text { years } \\
159 / 677\end{array}$ & $\begin{array}{c}\text { Age at diabetes } \\
\text { diagnosis } \geq 60 \text { years } \\
147 / 503\end{array}$ & & \\
\hline Male & & $1.94(1.40-2.70)$ & & \\
\hline Age at diabetes diagnosis (per year) ${ }^{a}$ & & $1.04(1.003-1.08)$ & $1.05(1.02-1.09)$ & \\
\hline Ex-smoker & $1.65(1.15-2.37)$ & & & \\
\hline Current smoker & $2.20(1.44-3.36)$ & & & \\
\hline Any exercise in past 2 weeks & & & $2.11(1.06-4.20)$ & \\
\hline Metformin use & & & & $2.16(1.19-3.90)$ \\
\hline Calcium channel blocker use & & & $2.37(1.39-4.06)$ & \\
\hline Fasting serum glucose $(\mathrm{mmol} / \mathrm{l})$ & & & & $0.88(0.77-0.99)$ \\
\hline Total serum cholesterol (per $1 \mathrm{mmo} / \mathrm{l})$ & & & $0.68(0.52-0.88)$ & \\
\hline 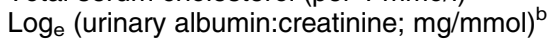 & $0.86(0.77-0.96)$ & & & $0.75(0.60-0.94)$ \\
\hline
\end{tabular}

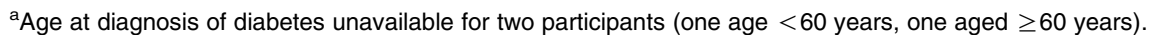

${ }^{b} \mathrm{~A} 2.72$-fold increase in urinary albumin:creatinine ratio (ACR) corresponds to an increase of 1 in $\log _{e}(A C R)$.

In the case of the main solid organ cancers, our significantly increased IRR of 1.36 for colorectal cancer in type 2 diabetic patients is consistent with those from meta-analyses of case-control and cohort studies (between 1.15 and 1.42) (3, 20, 30). Meta-analyses have also shown that this association is stronger among males than females (3) and our data indicate that older men (aged $\geq 75$ years) are at particular risk. In competing risk modelling, an older age at diagnosis, recent exercise and use of calcium channel blocking drugs were positively associated with colorectal cancer in the FDS cohort, while there was an inverse association with total serum cholesterol.

An effect of age at diagnosis on colorectal cancer incidence, which was probably the main contributor to the same association for all-cause cancer, has been reported previously. Consistent with the present data, one study showed that there was no association between diabetes and colorectal cancer if the diagnosis of diabetes was made before 60 years of age whereas a significant positive association was seen when diabetes was diagnosed later in life (31). This finding was attributed to dietary modification as part of the management of younger patients which might, in turn, attenuate subsequent colorectal cancer risk. Alternatively, there may be ascertainment bias in that older patients diagnosed with diabetes may be screened more intensively for age-related co-morbidities such as cancer. Although we employed a competing risk analysis, it is also possible that surviving relatively insulin-sensitive patients diagnosed at a younger age and at reduced risk of cardiovascular disease were overrepresented in our cohort. Such a survivor bias may also explain the apparently paradoxical positive relationship between recent exercise and colorectal cancer in our cohort. Although exercise should be protective against colon cancer (32), there is no clear relationship in the case of rectal cancer (33). There is also some evidence that physical activity over a lifetime is more important than recent exercise, such as assessed in the FDS, in gastrointestinal cancer prevention (34).

We found a positive association between use of calcium channel blockers and colorectal cancer that may also have reflected confounding. Those patients who were more aggressively treated for cardiovascular risk factors such as hypertension may have been less likely to die of cardiovascular disease and thus more likely to develop subsequent cancer. Alternatively, those requiring such medication were at inherently higher risk of colon cancer due to lifestyle factors common to cardiovascular risk and colorectal cancer. However, laboratory and clinical evidence that this group of drugs directly predisposes to cancer emerged in the 1990s (35). Most subsequent clinical studies have failed to confirm this link, including for colorectal cancer $(36,37)$, but the original positive reports were in older patients $(38,39,40)$ and most of our colorectal cancer cases were in those aged $\geq 75$ years. It is also possible that diabetes may act in concert with calcium channel blockers to increase cancer risk. It is reassuring, given recent controversies (41), that we did not find an association between renin-angiotensin blocking drugs and cancer in our cohort. The inverse association between total serum cholesterol and colorectal cancer risk observed in our cohort is not novel outside the context of diabetes $(42,43,44)$ and may reflect preclinical effects of malignancies on cholesterol absorption, transport, metabolism and/or utilisation $(44,45)$.

We did not find that prostate cancer incidence was influenced by diabetes. An apparently protective effect of diabetes $(20,29)$ has not been a consistent finding and may depend on factors such as duration of glycaemic exposure (7). Fasting serum glucose and albuminuria were inversely associated with prostate cancer in our cohort, while metformin therapy proved a positive associate. The inverse association with glycaemia has been documented in a range of other studies (46), 
including one that used a competing risk approach (47). As with cholesterol and colorectal cancer $(44,45)$, malignancies such as prostate cancer may have preclinical effects on glucose metabolism (46). In a study of non-diabetic individuals, baseline albuminuria was significantly correlated with the subsequent incidence of cancer (48), but the low plasma glucose concentrations in those men in our cohort who went on to be diagnosed with prostate cancer relative to those who did not may have confounded this association in this study. Alternatively, those with a low urinary albumin:creatinine ratio were those who were at low cardiovascular risk (49) and thus a survivor subset at risk of the later development of malignancy.

The positive association between prostate cancer and metformin therapy in our cohort runs contrary to accumulating data from both animal and human studies, suggesting that metformin has anti-cancer effects (12), a recent large Danish population-based study showing a reduced relative risk $(\mathrm{RR})$ for metformin users for any cancer (50), and the suggestion of a protective effect against prostate cancer in an epidemiological survey (51). However, a nested case-control study from a UK general practice database showed that metformin did not decrease the risk of prostate cancer (52). In secondary analyses, prostate cancer risk was found to increase as a function of the number of metformin prescriptions dispensed (52). The authors suggested that one possible explanation may relate to metformin-specific effects on the hormonal profile of men with diabetes, with better glycaemic control associated with higher serum testosterone concentrations and thus a greater risk of prostate cancer. In a study of men who underwent radical prostatectomy for prostate cancer, diabetes was associated with an increased risk of recurrence regardless of whether they were treated with metformin (53). Consistent with the results of the large Danish study (50), we did not find that blood glucose-lowering therapies other than metformin were independently associated with cancer.

There was no association between type 2 diabetes and breast cancer in our cohort. This may have reflected the relatively small number of events, which also precluded an assessment of predictive variables. Data from a recent meta-analysis support a $20 \%$ increase in the risk of breast cancer in diabetic women (4). Hyperglycaemia and insulin resistance are strong associates (54) and metformin therapy may be protective (12). Interestingly and consistent with the present findings, a recent Canadian administrative database study found no association between type 2 diabetes and breast cancer after allowing for initial detection bias (20). The IRR for pancreatic cancer in our diabetic patients $(2.26)$ is consistent with relative risks of between 1.82 and 2.17 in a variety of studies including pooled meta-analyses (55). This includes patients developing pancreatic cancer after many years of diabetes, especially in men (22), which addresses the issue of reverse causality.
Our matched controls were selected to have no documented evidence of diabetes during follow-up, mainly because we were concerned that there were patients with undiagnosed diabetes at the start of follow-up. This may, in turn, have influenced subsequent cancer risk and attenuated diabetes effects if these patients had been included. It is of interest that IRRs for the FDS cohort relative to national notifications were, by contrast, higher in all cases especially for pancreatic cancer. This provides some support for our approach of matching on postcode, a surrogate marker of socio-economic status and environmental exposures, as well as age and gender, as has been done by others (20).

Our study had limitations. First, the number of subjects and thus cancer events was low compared with those of most administrative database and intervention studies. This has been an issue for many similar detailed epidemiological studies $(3,4,6,7,12,25,30$, $31,56)$, a number of which had smaller sample sizes than this study. Secondly, we may have recruited relatively healthy diabetic patients into the FDS, but the FDS cohort appears representative of diabetes in the local community (15) and this potential source of bias would be offset through diabetic patients being more likely to seek medical treatment including assessments that might detect malignancy. Thirdly, we had limited power to examine site-specific cancers and their relationship with diabetes and could not reliably determine agespecific IRRs or possible changes in IRR by calendar year. Lastly, despite evidence that diabetes worsens prognosis after diagnosis of malignancy (57), we did not have sufficient cancer-related deaths to meaningfully examine a relationship with diabetes. The strengths of the FDS include its well characterised community-dwelling patients who have a low rate of migration out of Western Australia (58), the availability of a comprehensive validated linkage system for ascertainment of cancer events (19), and use of statistical modelling that allowed examination of the risk of cancer while accounting for the occurrence of competing events.

The clinical implications of this study are various. The increased incidence of all-cause cancer is justification for adopting recommended cancer screening strategies as part of diabetes management if they are not being implemented as part of other aspects of clinical care. In some cases, such as for colorectal cancer in men aged $\geq 75$ years, there is a strong argument for intensified screening practices. Although colonoscopic screening has been recommended for all type 2 patients about to start insulin therapy (56), our data do not provide support for this suggestion, especially in those patients diagnosed at a younger age. The positive association between metformin therapy and prostate cancer incidence found in this and other studies (52) needs to be further evaluated. The benefits of metformin for cardiovascular disease prevention (59) are likely to more than compensate for 
any potential increase in prostatic cancer risk in older diabetic males, but there may be some specific clinical situations in which metformin should be avoided. As changes in cardiovascular disease management improve outcome in diabetic patients (60), diagnosis and treatment of cancer will become a more important part of diabetes care.

\section{Supplementary data}

This is linked to the online version of the paper at http://dx.doi.org/10. 1530/EJE-12-0053.

\section{Declaration of interest}

The authors declare that there is no conflict of interest that could be perceived as prejudicing the impartiality of the research reported.

\section{Funding}

The FDS was supported by the Raine Foundation, University of Western Australia. D J Magliano is supported by a Victorian Cancer Agency Fellowship, J E Shaw by a National Health and Medical Research Council Senior Research Fellowship and T M E Davis by a National Health and Medical Research Council Practitioner Fellowship.

\section{Author contribution statement}

D J Magliano initiated the analyses and produced the first draft of the paper. W A Davis, senior biostatistician associated with the FDS, took responsibility for data linkage and the analysis and initial interpretation of the data. J E Shaw contributed to data interpretation and provided critical review of the paper. D G Bruce, co-investigator of the FDS, contributed to data interpretation and provided critical review of the paper. T M E Davis, the principal investigator of the FDS, assisted with analysis and interpretation and produced the final version of the paper.

\section{Acknowledgements}

The authors are grateful to FDS staff for help with collecting and recording clinical information. They also thank the Biochemistry Department at Fremantle Hospital and Health Service for performing laboratory tests, and the Diabetic Education, Podiatry and Dietetic Departments for assistance with recruitment of patients.

\section{References}

1 El-Serag HB, Hampel H \& Javadi F. The association between diabetes and hepatocellular carcinoma: a systematic review of epidemiologic evidence. Clinical Gastroenterology and Hepatology 20064 369-380. (doi:10.1016/j.cgh.2005.12.007)

2 Huxley R, Ansary-Moghaddam A, Berrington de Gonzalez A, Barzi F \& Woodward M. Type-II diabetes and pancreatic cancer: a meta-analysis of 36 studies. British Journal of Cancer 200592 2076-2083. (doi:10.1038/sj.bjc.6602619)

3 Luo W, Cao Y, Liao C \& Gao F. Diabetes mellitus and the incidence and mortality of colorectal cancer: a meta-analysis of twenty four cohort studies. Colorectal Disease 2012 In press. (doi:10.1111/ j.1463-1318.2011.02875.x)

4 Larsson SC, Mantzoros CS \& Wolk A. Diabetes mellitus and risk of breast cancer: a meta-analysis. International Journal of Cancer 2007 121 856-862. (doi:10.1002/ijc.22717)
5 Friberg E, Orsini N, Mantzoros CS \& Wolk A. Diabetes mellitus and risk of endometrial cancer: a meta-analysis. Diabetologia $2007 \mathbf{5 0}$ 1365-1374. (doi:10.1007/s00125-007-0681-5)

6 Larsson SC, Orsini N, Brismar K \& Wolk A. Diabetes mellitus and risk of bladder cancer: a meta-analysis. Diabetologia $2006 \mathbf{4 9}$ 2819-2823. (doi:10.1007/s00125-006-0468-0)

7 Kasper JS \& Giovannucci E. A meta-analysis of diabetes mellitus and the risk of prostate cancer. Cancer Epidemiology, Biomarkers $\mathcal{E}$ Prevention 200615 2056-2062. (doi:10.1158/1055-9965.EPI06-0410)

8 Giovannucci E, Harlan DM, Archer MC, Bergenstal RM, Gapstur SM, Habel LA, Pollak M, Regensteiner JG \& Yee D. Diabetes and cancer: a consensus report. CA: A Cancer Journal for Clinicians 201060 207-221. (doi:10.3322/caac.20078)

9 Elashoff M, Matveyenko AV, Gier B, Elashoff R \& Butler PC. Pancreatitis, pancreatic, and thyroid cancer with glucagon-like peptide-1-based therapies. Gastroenterology 2011 141 150-156. (doi:10.1053/j.gastro.2011.02.018)

10 Lewis JD, Ferrara A, Peng T, Hedderson M, Bilker WB, Quesenberry CP Jr, Vaughn DJ, Nessel L, Selby J \& Strom BL. Risk of bladder cancer among diabetic patients treated with pioglitazone: interim report of a longitudinal cohort study. Diabetes Care 201134 916-922. (doi:10.2337/dc10-1068)

11 Ruiter R, Visser LE, van Herk-Sukel MP, Coebergh JW, Haak HR, Geelhoed-Duijvestijn PH, Straus SM, Herings RM \& Stricker BH. Risk of cancer in patients on insulin glargine and other insulin analogues in comparison with those on human insulin: results from a large population-based followup study. Diabetologia 201255 51-62. (doi:10.1007/s00125011-2312-4)

12 Decensi A, Puntoni M, Goodwin P, Cazzaniga M, Gennari A, Bonanni B \& Gandini S. Metformin and cancer risk in diabetic patients: a systematic review and meta-analysis. Cancer Prevention Research 20103 1451-1461. (doi:10.1158/1940-6207.CAPR10-0157)

13 Fine JP \& Gray RJ. A proportional hazards model for the subdistribution of a competing risk. Journal of the American Statistical Association $1999 \mathbf{9 4}$ 496-509. (doi:10.1080/ 01621459.1999.10474144)

14 Davis TM, Bruce DG \& Davis WA. Cohort Profile: The Fremantle Diabetes Study (FDS). International Journal of Epidemiology 2012 In press. (doi:10.1093/ije/dys065)

15 Davis TM, Zimmet P, Davis WA, Bruce DG, Fida S \& Mackay IR. Autoantibodies to glutamic acid decarboxylase in diabetic patients from a multi-ethnic Australian community: the Fremantle Diabetes Study. Diabetic Medicine 200017 667-674. (doi:10. 1046/j.1464-5491.2000.00359.x)

16 Fernandez RC, Driscoll TR, Glass DC, Vallance D, Reid A, Benke G \& Fritschi L. A priority list of occupational carcinogenic agents for preventative action in Australia. Australian and New Zealand Journal of Public Health 201236 111-115. (doi:10.1111/j. 1753-6405.2011.00849.x)

17 Fritschi L, Hoving JL, Sim MR, Del Monaco A, MacFarlane E, McKenzie D, Benke G \& de Klerk N. All cause mortality and incidence of cancer in workers in bauxite mines and alumina refineries. International Journal of Cancer 2008123 882-887. (doi:10.1002/ijc.23554)

18 AIHW (Australian Institute of Health and Welfare) \& AACR (Australasian Association of Cancer Registries) 2008. Cancer in Australia: an overview, 2008. Cancer series no. 46. Cat. no. CAN 42. Canberra: AIHW.

19 Holman CD, Bass AJ, Rouse IL \& Hobbs MS. Population-based linkage of health records in Western Australia: development of a health services research linked database. Australian and New Zealand Journal of Public Health 199923 453-459. (doi:10.1111/j. 1467-842X.1999.tb01297.x)

20 Johnson JA, Bowker SL, Richardson K \& Marra CA. Time-varying incidence of cancer after the onset of type 2 diabetes: evidence of potential detection bias. Diabetologia $2011 \quad 54$ 2263-2271. (doi:10.1007/s00125-011-2242-1) 
21 Thiebaut AC \& Benichou J. Choice of time-scale in Cox's model analysis of epidemiologic cohort data: a simulation study. Statistics in Medicine 200423 3803-3820. (doi:10.1002/sim.2098)

22 Jee SH, Ohrr H, Sull JW, Yun JE, Ji M \& Samet JM. Fasting serum glucose level and cancer risk in Korean men and women. Journal of the American Medical Association 2005293 194-202. (doi:10.1001/jama.293.2.194)

23 Inoue M, Iwasaki M, Otani T, Sasazuki S, Noda M \& Tsugane S. Diabetes mellitus and the risk of cancer: results from a large-scale population-based cohort study in Japan. Archives of Internal Medicine 2006166 1871-1877. (doi:10.1001/archinte.166.17. 1871)

24 Ferguson RD \& LeRoith D. Obesity, type 2 diabetes and cancer. In Insulin-like Growth Factors and Cancer: From Basic Biology to Therapeutics, D LeRoith (ed) pp 37-72, 2011, New York: Springer.

25 Yeh H-C, Platz EA, Wang N-Y, Visvanathan K, Helzlsouer KJ \& Brancati FL. A prospective study of the associations between treated diabetes and cancer outcomes. Diabetes Care 201235 113-118. (doi:10.2337/dc11-0255)

26 Wideroff L, Gridley G, Mellemkjaer L, Chow WH, Linet M, Keehn S, Borch-Johnsen K \& Olsen JH. Cancer incidence in a populationbased cohort of patients hospitalized with diabetes mellitus in Denmark. Journal of the National Cancer Institute 199789 1360-1365. (doi:10.1093/jnci/89.18.1360)

27 Lo SF, Chang SN, Muo CH, Chen SY, Liao FY, Dee SW, Chen PC \& Sung FC. Modest increase in risk of specific types of cancer types in type 2 diabetes mellitus patients. International Journal of Cancer 2012 In press. (doi:10.1002/ijc.27597)

28 Turturro F, Friday E \& Welbourne T. Hyperglycemia regulates thioredoxin-ROS activity through induction of thioredoxininteracting protein (TXNIP) in metastatic breast cancer-derived cells MDA-MB-231. BMC Cancer 20077 96. (doi:10.1186/14712407-7-96)

29 Vigneri P, Frasca F, Sciacca L, Pandini G \& Vigneri R. Diabetes and cancer. Endocrine-Related Cancer 200916 1103-1123. (doi:10.1677/ERC-09-0087)

30 Larsson SC, Orsini N \& Wolk A. Diabetes mellitus and risk of colorectal cancer: a meta-analysis. Journal of the National Cancer Institute 200597 1679-1687. (doi:10.1093/jnci/dji375)

31 La Vecchia C, Negri E, Decarli A \& Franceschi S. Diabetes mellitus and colorectal cancer risk. Cancer Epidemiology, Biomarkers $\mathcal{E}$ Prevention 19976 1007-1010.

32 Watson AJ \& Collins PD. Colon cancer: a civilization disorder. Digestive Diseases 201129 222-228. (doi:10.1159/000323926)

33 Coyle YM. Lifestyle, genes, and cancer. Methods in Molecular Biology 2009472 25-56. (doi:10.1007/978-1-60327-492-0_2)

34 Wolin KY \& Tuchman H. Physical activity and gastrointestinal cancer prevention. Recent Results in Cancer Research $2011 \mathbf{1 8 6}$ 73-100. (doi:10.1007/978-3-642-04231-7_4)

35 Pahor M \& Furberg CD. Calcium antagonists and cancer: causation or association? Cardiovascular Drugs and Therapy 1998 12 511-513. (doi:10.1023/A:1007706529684)

36 Boudreau DM, Koehler E, Rulyak SJ, Haneuse S, Harrison R \& Mandelson MT. Cardiovascular medication use and risk for colorectal cancer. Cancer Epidemiology, Biomarkers \& Prevention 200817 3076-3080. (doi:10.1158/1055-9965.EPI-08-0095)

37 Rosenberg L, Rao RS, Palmer JR, Strom BL, Stolley PD, Zauber AG, Warshauer ME \& Shapiro S. Calcium channel blockers and the risk of cancer. Journal of the American Medical Association 1998279 1000-1004. (doi:10.1001/jama.279.13.1000)

38 Fitzpatrick AL, Daling JR, Furberg CD, Kronmal RA \& Weissfeld JL. Use of calcium channel blockers and breast carcinoma risk in postmenopausal women. Cancer $1997 \quad 80 \quad 1438-1447$. (doi:10.1002/(SICI)1097-0142(19971015)80:8 < 1438::AID-CN CR11> 3.0.CO;2-6)

39 Pahor M, Guralnik JM, Ferrucci L, Corti MC, Salive ME, Cerhan JR, Wallace RB \& Havlik RJ. Calcium-channel blockade and incidence of cancer in aged populations. Lancet $1996 \mathbf{3 4 8} 493-497$. (doi:10.1016/S0140-6736(96)04277-8)
40 Pahor M, Guralnik JM, Salive ME, Corti MC, Carbonin P \& Havlik RJ. Do calcium channel blockers increase the risk of cancer? American Journal of Hypertension 19969 695-699. (doi:10.1016/ 0895-7061(96)00186-0)

41 Ocampo NV, Tafreshi J, Hauschild CL \& Pai RG. Cardiovascular medications and risk of cancer. American Journal of Cardiology 2011108 1045-1051. (doi:10.1016/j.amjcard.2011.05.041)

42 Schatzkin A, Hoover RN, Taylor PR, Ziegler RG, Carter CL, Albanes D, Larson DB \& Licitra LM. Site-specific analysis of total serum cholesterol and incident cancer in the National Health and Nutrition Examination Survey I Epidemiologic Follow-up Study. Cancer Research 198848 452-458.

43 Iso H, Ikeda A, Inoue M, Sato S \& Tsugane S. Serum cholesterol levels in relation to the incidence of cancer: the JPHC study cohorts. International Journal of Cancer 2009125 2679-2686. (doi:10.1002/ijc.24668)

44 Ahn J, Lim U, Weinstein SJ, Schatzkin A, Hayes RB, Virtamo J \& Albanes D. Prediagnostic total and high-density lipoprotein cholesterol and risk of cancer. Cancer Epidemiology, Biomarkers $\mathcal{E}$ Prevention 200918 2814-2821. (doi:10.1158/1055-9965.EPI08-1248)

45 Jacobs DR Jr, Hebert B, Schreiner PJ, Sidney S, Iribarren C \& Hulley S. Reduced cholesterol is associated with recent minor illness: the CARDIA Study. Coronary artery risk development in young adults. American Journal of Epidemiology 1997146 558-564. (doi:10.1093/oxfordjournals.aje.a009314)

46 Hsing AW, Sakoda LC \& Chua S Jr. Obesity, metabolic syndrome, and prostate cancer. American Journal of Clinical Nutrition $2007 \mathbf{8 6}$ s843-s857.

47 Van Hemelrijck M, Garmo H, Holmberg L, Walldius G, Jungner I, Hammar N \& Lambe M. Prostate cancer risk in the Swedish AMORIS study: the interplay among triglycerides, total cholesterol, and glucose. Cancer 2011117 2086-2095. (doi:10.1002/ cncr.25758)

48 Jorgensen L, Heuch I, Jenssen T \& Jacobsen BK. Association of albuminuria and cancer incidence. Journal of the American Society of Nephrology 200819 992-998. (doi:10.1681/ASN. 2007060712)

49 Davis WA \& Davis TM. Cardiovascular risk prediction in adults with type 1 diabetes: the Fremantle Diabetes Study. Diabetes Research and Clinical Practice 201090 e75-e78. (doi:10.1016/j. diabres.2010.09.015)

50 Andersson C, Vaag A, Selmer C, Schmiegelow M, Sorensen R, Lindhardsen J, Gislason GH, Kober L \& Torp-Pedersen C. Risk of cancer in patients using glucose-lowering agents: a nationwide cohort study of 3.6 million people. BMJ Open 20122 e000433. (doi:10.1136/bmjopen-2011-000433)

51 Wright JL \& Stanford JL. Metformin use and prostate cancer in Caucasian men: results from a population-based case-control study. Cancer Causes \& Control 200920 1617-1622. (doi:10. 1007/s10552-009-9407-y)

52 Azoulay L, Dell'Aniello S, Gagnon B, Pollak M \& Suissa S. Metformin and the incidence of prostate cancer in patients with type 2 diabetes. Cancer Epidemiology, Biomarkers \& Prevention 201120 337-344. (doi:10.1158/1055-9965.EPI-10-0940)

53 Patel T, Hruby G, Badani K, Abate-Shen C \& McKiernan JM. Clinical outcomes after radical prostatectomy in diabetic patients treated with metformin. Urology 201076 1240-1244. (doi:10.1016/j.urology.2010.03.059)

54 Sieri S, Muti P, Claudia A, Berrino F, Pala V, Grioni S, Abagnato CA, Blandino G, Contiero P, Schunemann HJ \& Krogh V. Prospective study on the role of glucose metabolism in breast cancer occurrence. International Journal of Cancer 2012130 921-929. (doi:10.1002/ijc.26071)

55 Hsu C \& Saif MW. Diabetes and pancreatic cancer. Highlights from the "2011 ASCO Annual Meeting". Chicago, IL, USA; June 3-7, 2011. JOP: Journal of the Pancreas 201112 330-333.

56 Berster JM \& Goke B. Type 2 diabetes mellitus as risk factor for colorectal cancer. Archives of Physiology and Biochemistry 2008 114 84-98. (doi:10.1080/13813450802008455) 
57 Zhou XH, Qiao Q, Zethelius B, Pyorala K, Soderberg S, Pajak A, Stehouwer CD, Heine RJ, Jousilahti P, Ruotolo G, Nilsson PM, Calori G \& Tuomilehto J. Diabetes, prediabetes and cancer mortality. Diabetologia 201053 1867-1876. (doi:10.1007/ s00125-010-1796-7)

58 Bradshaw PJ, Jamrozik K, Jelfs P \& Le M. Mobile Australians: a moving target for epidemiologists. Medical Journal of Australia 2000172566.

59 Bianchi C, Miccoli R, Daniele G, Penno G \& Del Prato S. Is there evidence that oral hypoglycemic agents reduce cardiovascular morbidity/mortality? Yes. Diabetes Care 200932 (Suppl 2) S342-S348. (doi:10.2337/dc09-S336)
60 Ford ES. Trends in the risk for coronary heart disease among adults with diagnosed diabetes in the U.S.: findings from the National Health and Nutrition Examination Survey, 1999-2008. Diabetes Care 201134 1337-1343. (doi:10.2337/ dc10-2251)

Received 20 January 2012

Revised version received 9 August 2012

Accepted 14 August 2012 